\title{
探究高层建筑深基坑支护施工过程的控制要点
}

\author{
孔令军 \\ 广西顺安建筑工程有限公司 \\ DOI:10.32629/btr.v1i6.1727
}

[摘 要] 近些年来, 我国城市化进程持续推进,城市建筑工程项目的数量也在不断增加, 其中多以高层建筑为主。深基坑支护施工 技术是高层建筑工程施工中常用的技术类型,本文将对其具体应用进行深入的探索研究,希望可以为建筑行业发展提供助力。

[关键词]深基坑支护；建筑工程；应用

1 建筑工程深基坑支护施工特点及常用技术介绍

1.1 建筑工程深基坑支护施工的特点

首先, 基坑深度不断加大。随着我国城市化进程的持续 推进, 我国城市土地资源不足的问题逐渐突显出来, 为了实 现土地资源的最大化利用, 我国许多建筑商都在大力开发地 下建筑 ${ }^{[1]}$ 。在这样的情况下, 建筑工程施工中的基坑就呈现 出不断加深的趋势。据调查, 在一些技术较为发达的地区, 建筑工程基坑深度甚至可以达到二十米。结合建筑行业发展 现状来看, 这并不是极限, 我国建筑工程基坑深度仍在向更 深的层次发展。基坑支护作业施工, 需要从基坑深度入手, 需要根据其实际深度选择有效的基坑支护手段,而针对不同 深度, 不同地质条件和不同作用的基坑所需要的基坑支护方 案是不同的。其中, 灌注桩内支撑支护技术、灌注桩斜拉针 技术和地下连续墙支护技术等都是较为常用的。在实际的施 工过程中, 基坑支护作用和土方开挖之间的联系是较为紧密 的, 如果两者之间的协调性相对较差, 则很容易导致超挖和 提前开挖等问题的发生, 进而对基坑支护工作造成不良影 响。也就是说, 在深基坑施工过程中, 需要保证深基坑支护和 土方开挖的协调性。

其次, 施工条件变得越来越复杂。近些年来, 随着我国建 筑工程项目数量的持续增加, 工程施工所面临的条件也变得 越来越复杂。尤其是在深基坑支护施工技术应用的的过程中, 会对工程现场地层造成极大的破坏和影响, 很容易对周边建 筑的安全性和稳定性造成损害。在推进深基坑施工的过程中, 支护施工是尤为重要的, 但是其所对应的施工难度也相对较 大。首先, 施工队伍建设工作较为复杂, 通常情况下, 建筑工 程中深基坑施工队伍的数量相对较大, 而不同队伍之间的默 契度几乎为零, 在这种情况下, 会导致流水施工工序不能得 到很好的衔接, 甚至会对工程的施工质量造成不良影响 ${ }^{[2]}$ 。 同时, 就工程中的施工人员来说, 存在人员素质参差不齐的 情况, 像很多施工人员不具备施工能力, 甚至没有岗位证和 特种工操作证, 这就导致施工过程中的专业性问题难以得到 解决, 不利于工程的有效推进。

最后, 安全事故发生的风险较高。建筑工程深基坑施工 会严重破坏工程现场地质环境, 导致安全事故发生风险大幅 度提升。若是在施工过程中支护不到位, 很容易引发坍塌事
故, 不仅会造成施工成本的增加, 还会威胁到相关人员的人 身安全。工程的实际开展过程中, 其所对应的难度主要表现 在深基坑支护方面, 需要在实际施工过程中, 对边坡进行修 整, 大部分工程施工通常采用工人操作与器械设备相结合的 方式, 在这一情况基础上, 一旦施工不当, 就会导致危险问题 的发生, 像欠挖和超挖问题是尤为常见的。例如: 运用机械 设备开展边坡挖掘工作时, 一旦机械设备不能对边坡挖掘坡 度进行有效控制, 就会导致边坡坡度高低不一进而不利于下 一道工序的施工。

1.2 建筑工程中常用的深基坑支护施工技术

其一, 土钉墙施工技术。该技术主要是采用加固土体、 混凝土以及土钉群构建支护结构体系, 具有成本低、施工方 便等优势, 可以有效的抵制地层压力。在采用这种技术施工 过程中, 需要对水泥浆注入程序进行严格的把控, 同时做好 地下排水工作, 如此才能保障施工质量。

其二, 护坡桩施工技术。该技术是通过钻孔成桩的方式 起到加固和支护的效果, 具有成桩率高、施工方便等优点, 比较适用于一些环境条件较为复杂的建筑工 ${ }^{[3]}$ 。在应用该技 术的过程中, 最需要注意的点就是整个施工作业过程必须符 合工程设计相关标准, 尤其需要对钻孔注浆作业进行全面把 控, 保障注浆的质量。

其三, 土层针杆施工技术。相较于其它深基坑支护施工 技术, 土层针杆施工技术水平较高, 在施工中需要使用到针 杆钻机。在应用该技术时, 为了保障施工质量, 需要在施工前 做好测量工作, 并在施工过程中对钻机钻孔深度和位置存在 的偏差进行严格的控制, 同时做好孔内障碍物的清除工作。

1.3 深基坑支护使用技术在建筑工程中应用的要求

首先, 对外部条件进行合理的设计, 最大程度的降低外 部条件可能对施工产生的不利影响。其次, 结合工程施工方 案科学选择深基坑支护技术, 保障技术实施和工程建设要求 的契合。最后, 提高建筑地基工程的稳固性。深基坑支护施 工技术的应用必须起到提高基坑周边地基稳固性的效果。

\section{2 深基坑支护施工技术在建筑工程中的具体应用分析}

在深基坑支护施工过程中, 施工人员对边坡进行修理时, 很容易出现超挖现象, 主要是由于在对深基坑进行挖掘时, 一 般情况下都使用较大的挖掘设备, 这些设备体积较大, 不能对 
深基坑进行细节操作, 这就需要施工人员对基坑进行适当的 调整, 通过人工修理的方法来弥补挖掘设备存在的不足, 从而 提高施工质量。但有的施工人员技术水平不高, 在使用挖掘机 进行挖掘时, 不能有效控制设备, 超挖现象经常出现, 这不但 给后续施工人员带来较大的难度, 增加了施工人员的工作量, 还降低了施工质量。此外, 有的后续施工人员专业水平不高, 不能对基坑进行有效填补, 导致基坑平整度没有达到规定的 要求。开展深基坑支护施工技术在建筑工程中的具体应用分 析, 实现支护施工技术应用水平的全面提升, 可以为我国建筑 工程的开展奠定稳定坚实的基础。

\section{1 施工前进行工程勘探}

在建筑工程施工前, 施工单位一定要事先到工程现场进 行实地勘探, 掌握现场的地理环境条件, 为工程施工方案设计 提供详实可靠的依据。对于需要进行支护作业的地段, 要通过 勘探掌握其地质情况、水文条件, 具体是对其土层结构、土质、 地下水情况进行全面的测量和评价, 从而有针对性的制定支 护方案。除此之外, 还需对支护施工周边建筑的地基情况进行 的了解掌握, 明晰其能够承受的极限, 这样可以将深基坑支护 施工对周边建筑产生的不利影响控制在最小的范围内。

\section{2 进行土层针杆施工}

在土层错杆施工中, 施工人员要在建筑地下室围护结构 和未开挖的基坑立壁上进行打孔作业,之后将孔型修饰成柱 状, 向其中加入钢绞线等抗拉性能较强的次啊来, 最后向其 中灌注混凝土, 实现针杆和土层的紧密结合, 提升维护结构 和基坑立壁的抗拉性能。在施工中需要着重注意的点包括以 下几个部分: 其一, 对桩位、孔深以及孔壁强度进行明确, 为钻孔施工提供依据。其二, 在钻孔完成后, 必须对孔内进行 细致的清理。其三, 在安置针杆时最好采用螺旋钻杆施工法。

\section{3 土钉支护施工}

土钉支护施工的目的是提升基坑支护结构的稳定性, 在 施工设计阶段, 要结合深基坑支护施工的相关标准对土钉强 度和拉力进行合理的设置, 最好通过拉拔试验确定。同时, 对土钉支护的孔深进行科学计算并作出明确标注。需格外注 意是, 混凝土灌注施工前, 必须要对混凝土的配合比进行科
学设计, 保障其与施工设计标准相符合。

2.4 护坡桩施工

护坡桩施工技术常用于地质环境条件较为复杂的建筑 工程中, 其具体施工流程如下: 首先, 对桩基的预定深度进行 设置, 以此为依据使用螺旋钻机下钻到相应的位置。其次, 进行压浆。在这一环节, 施工人员要对浆液压入的顺序进行 合理选择, 最理想的情况是从下向上, 且浆液压入界限位置 必须和地下水或是无塌孔位置保持一致。最后, 当浆液达到 相应的界限位置之后, 将螺旋钻机提出, 投放钢筋笼和骨料, 并进行高压补浆处理。

\section{5 施工质量控制措施}

基于上述深基坑支护施工程序, 在施工过程中, 应该采 取以下几项施工质量控制措施：首先, 结合设计方案对支护 结构尺寸上存在的误差进行检查, 一经发现, 必须要及时和 设计单位进行沟通, 结合施工实际情况制定合理有效的解决 措施。需要特别注意支护结构的极限状态, 设计单位要结合 基坑深度对石挡墙结构进行合理设计, 避免其超出极限状 态。在必要的情况下, 可以采用多支点结构替代单支点结构, 以此弥补其在承重能力方面存在的不足。其次, 在整个施工 过程中, 必须安排专业部门对施工状态进行跟踪检查, 以便 及时发现和解决深基坑变形和渗水等问题。

\section{3 结束语}

综上所述, 随着我国高层建筑工程项目数量的增加, 深 基坑支护施工技术的应用变得越来越广泛, 为了提升技术实 施的效果, 本文对其在建筑工程中的具体应用进行了详细的 阐述, 希望能够为技术的发展创新提供一定的思路, 推动我 国建筑行业持续向前发展。

\section{[参考文献]}

[1]王荣军.深基坑支护施工技术在建筑工程中的应用 运用[J].江西建材,2016(08):116+122.

[2]韦希斌, 探究建筑工程施工中深基坑支护的施工技术 管理[J].门窗,2016(05):111-112.

[3]曹雄伟.试分析建筑工程施工中深基坑支护的施工技 术管理[J].绿色环保建材,2016(09):86. 